\title{
Motivations of Using Social Media Through Smartphones Among University Students in the United Arab Emirates
}

\author{
Khayrat Ayyad \\ University of Sharjah, Sharjah, UAE
}

\begin{abstract}
The aim of the study was to investigate gratifications of using social media among university students in the United Arab Emirates. Adopting the uses and gratification approach, the study investigates how the students utilize social media to gratify their personal, social, psychological, and educational needs. The study uses a questionnaire to collect data from a sample of 420 students from two universities in the UAE: University of Sharjah and Zayed University. In each university, two colleges were selected to represent art colleges and sciences colleges. The findings of the study show that $69.3 \%$ of the students are accessing social media more than five hours daily. $79.0 \%$ of the students access the social media through their smartphones. The main social media accessed are WhatsApp, Instagram, and Facebook. The main reasons of using social media are seeking information, communicating with friends, consuming time, and following up public affairs.
\end{abstract}

Keywords: social media, motivations, smartphones, university's students, UAE

\section{Introduction}

The 21 st century has witnessed ever-increasing technological advances leaving an imprint on all aspects of life. One of these advances is the smartphone and its numerous applications or apps offering quick access to the Internet and social media. Social media have penetrated in the everyday life of Internet users, and the increasing pervasiveness of smartphones is only strengthening this phenomenon (Khan, 2017).

The United Arab Emirates (UAE) generally leads the Middle East Arab countries in ICT rankings, with a well-developed and technologically advanced telecom sector and high levels of mobile and broadband penetration.

According to the Global Information Technology Report (2016), the UAE occupies the first position in the Arab region in terms of the readiness of its telecommunications networks, according to a study published by the World Economic Forum in 2016, and 26th position globally among 139 countries. The network readiness index measures the capacity of an economy to benefit from information and communication technology, to increase competitiveness and development. The network readiness index in the report is based on information gathered by organizations, including the International Telecommunications Union, the World Bank, the United Nations, and other international organizations.

The UAE has two fixed network and mobile operators: the original incumbent Etisalat and operator du, which launched services in February 2007. Fixed-line competition increased recently with the TRA announcing in late 2015 that fixed network sharing had finally been implemented across the country with both operators

Khayrat Ayyad, Dr., College of Communication, University of Sharjah, Sharjah, UAE. 
now able to offer and market services in locations previously withheld.

In 2017, the broadband market in the UAE is one of the most advanced both regionally and globally. Prior to the fixed network sharing agreement introduced in late 2015, both Etisalat and Du operated FttH networks in separate areas-Du in the Dubai free trade zones and Etisalat in the rest of the country. Besides FttH/FttP, other internet technologies available in the UAE include ADSL, leased lines, Wi-Fi, and mobile networks.

The UAE government at both federal and emirate level has been proactive in the digital economy and digital media sectors, with programs to encourage computer and internet use. Like other countries in the Middle East, the UAE aims to transition into a "knowledge based and highly productive economy" by 2021 (BuddeComm Report, 2017).

As for the usage of new technology in the UAE, of the 9.58 million people of populations, around 8.81 million (92.0\%) are active internet users. Mobile phone usage in the UAE increased in March 2018 to 228.3 phones per 100 people; the increase in the use of mobile phones in the UAE also saw an increase in the number of telecom subscribers in March 2017, by more than 132,000 new subscriptions compared to February. This led to a jump in the total number of cumulative subscriptions to 19.835 million (BuddeComm Report, 2018).

\section{Social Media Usage in the UAE}

Social media is defined as the means of interactions among people in which they communicate, collaborate, and share information online in a social dialogue as creators of user-generated content in a virtual community (Gan, Lee, \& Li, 2017). It is a platform, where users can jointly investigate network contents, share their experience, and build up a relation for different purposes. Social media is operationally defined as the sum of blogs, social networking sites, micro blogs, content sharing sites, Wikis, and interactive video-gaming sites that allow users to co-construct and share content (Kuss \& Griffiths, 2017).

The year 2015 has proved to be a time of social media prominence with phenomenal digital growth in UAE and across the world. More than 5.4 million of internet users in the UAE (61.0\%) are active in the social media; nearly 4.6 million of them are accessing social media through mobile phones, which means that $85.2 \%$ of social media user's access their accounts through their mobile devices (Arabian Gazette, 2018).

Nevertheless, mobile users spend only three hours 45 minutes online on average. The PCs and laptops are not far behind, with $44 \%$ of internet users still using them to access the net. PC and laptop users spend more time online, on an average more than five hours. Tablet usage is slowly gaining momentum as witnessed by the $6 \%$ of internet users who go online using a tablet. However, tablet users spend on an average three hours and 35 minutes online (Ayyad, 2017).

\section{Theoretical Framework}

Since the advent of the mobile phone in the late nineties, it is witnessing successive developments made it one of the most popular means of communication between all segments of society, especially the youth. When it appeared, the basic function of the mobile phone was to make phone calls only, but now the mobile phone has many functions, especially those smartphones that have access to the Internet.

Research on the mobile phone indicates that the most popular category is the university youth category. This is due to the ability of the modern mobile phone and its ability to enter all forms of communication process, thus becoming an integrated social network in the hands of the individual and an interactive means of 
communication through different applications, interactive media, and diverse social networks (Sapacz, Rockman, \& Clark, 2016).

Social media have penetrated in the everyday life of Internet users, and the increasing pervasiveness of smartphones is only strengthening this phenomenon. Nowadays, these two technologies are intertwined, since smartphones are becoming more and more pervasive, especially in the student population.

The 21st century has witnessed ever-increasing technological advances leaving an imprint on all aspects of life. One of these advances is the smartphone and its numerous applications or apps offering quick access to the Internet and social media.

Many researches proposed social, psychological, and personal motivations for social media use among youth and adolescents. These motivations include entertainment, information seeking, personal utility, online communication, online self-disclosure, identity formation, social interaction, social relationship formation, mood regulation, and a need to conform to group norms (Griffiths, Kuss, \& Demetrovics, 2014).

Researchers have applied different theories and models to explain adolescent motivations of using social media. According to Throuvala (2019), two of the most prominent theories are the Self-Determination Theory and Uses and Gratifications Theory, where gratifications drive mobile social media use by emphasizing the affective, integrative, and mobile dimensions of adolescent motivations.

Rooted in the functional view of media, the uses and gratifications approach to media use assumes that audiences are aware of their social and psychological needs and actively seek the media to fulfill them (Michael, Wotring, \& Forrest, 1995). Therefore, the uses and gratifications approach assumes that audience members actively seek out the mass media, fulfill expectations, and actively select media and media content to satisfy individual needs (Stephen \& Owen, 2004). It may be argued that the uses and gratifications approach shifts the emphasis of media communication studies from the effect perspective to an audience perspective (Alonzo \& Aiken, 2004).

Leung (2003) argued that the most important assumption of this approach is that the audience is active and media use is goal-directed. Therefore, the public are self-aware-knowing and articulating their reasons for using the media — that they consider the media as a means of satisfying their needs.

Meanwhile, researches criticized the uses and gratifications approach in many ways. There have been three main lines of criticism: one related to its theoretical underpinnings and associated methods; another to its social and political implications; a third to its way of handling cultural phenomena (McQuail, 1997).

Despite these types of criticism, many researchers argue that this approach stands as a dominant paradigm. It has organized much work, continues to lend itself to further elaboration and application in research, and can provide a powerful framework for investigating the media in a wide social and cultural context (McQuail, 2010).

With the advent of digital media, many researchers argue that the uses and gratifications approach appears ideally suited to studying the Internet and new media (Lin \& Jeffries, 1998). While individuals can passively allow television content to wash over them, online technologies such as e-mail, bulletin boards, and chat rooms are interactive applications that require audience members to be active users.

Similarly, web users actively search out information when they click on links or employ search engines, suggesting web use is goal-directed and that users are aware of the needs they are attempting to satisfy. Many studies of web gratifications either relied on or adapted gratifications from traditional media studies. 
Later on, researchers realized that the unique attributes of the Internet led to gratifying the needs not served by other media such as personal fulfillment, social surveillance, identity, and free expression (Kaye \& Johnson, 2004).

The uses and gratifications approach is now widely accepted for nearly all kinds of mediated communication tools. Many studies applied this approach to examine audience motivations to use a certain type of mediated communication whenever a new communication technology is introduced. For example, the uses and gratification approach was adopted to study how university students use new technology, including VCRs and the Internet (Chan \& Fang, 2007). In this respect, the uses and gratification approach is applied in this study.

\section{Research Questions and Methodology}

As this study aims at investigating gratifications of using social media among university students in the UAE, it answers the following questions:

(1) What are patterns of using social media by university students in the UAE?

(2) What are main motivations among students to access social media through their smartphones?

(3) To what extent students use social media for academic purposes?

(4) Are gender and college of students affecting their motivations to use social media?

To answer the above questions, a questionnaire was designed to collect data from a sample of 420 students from two universities in the UAE: University of Sharjah (UoS) and Zayed University (ZU). In each university, four colleges were selected; two of them represent art programs and the others represent sciences programs.

Many researchers argued that universities are the most suitable place to study usage of new communication technologies. Junco, Heibergert, and Loken (2010) argued that universities are a suitable place for technological diffusion. Goldfarb (2006) also stated that universities taught students how to use the Internet and provide them with necessary facilities to go online.

All students in the UoS and ZU have facilities to access the Internet for various administrative and course-related purposes. Therefore, the Internet becomes a mass-mediated medium in university life. Students use it for a wide variety of academic purposes such as getting information and data to complete coursework, conducting research, and communicating with faculty members. Therefore, it may be argued that the UoS and ZU provide a good environment for the study.

\section{Finding of the Study}

Finding of the study will be presented in terms of research questions as follows.

\section{Research Q1: What Are Patterns of Using Social Media by University Students in the UAE?}

Daily use of social media. As for patterns of using social media among university students in the UAE, rate of surfing social media and media used to access social media are dealt with. The following table shows rate of accessing social media among university student in the UAE.

Table 1 shows that $68.6 \%$ of students are using social media five hours or more and around $18.0 \%$ uses social media between three and five hours. This finding indicates that nearly $87.0 \%$ of the university students in the UAE are using social media for more than three hours daily, which is considered as a highly rate of using social media according the international standards. 
As for the differences within studied universities, the above table indicates that there are no obvious differences in rate of using social media among students in both UoS and ZU. It seems that all university students may be considered as heavy users of social media.

Table 1

Daily Rate of Using Social Media Within Universities

\begin{tabular}{llll}
\hline Rate of usage & UoS & ZU & Total \\
\hline Less than an hour & $8(2.7 \%)$ & $3(2.5 \%)$ & $11(2.6 \%)$ \\
$1-3$ hours & $34(11.3 \%)$ & $12(10.0 \%)$ & $46(11.0 \%)$ \\
$3-5$ hours & $56(18.7 \%)$ & $19(15.8 \%)$ & $75(17.9 \%)$ \\
5 or more & $202(67.3 \%)$ & $86(71.7 \%)$ & $288(68.6)$ \\
Total & $300(100.0 \%)$ & $120(100.0 \%)$ & $420(100.0 \%)$ \\
\hline
\end{tabular}

Devices to access social media. In 2017, Statistics of International Telecommunications Unions indicate that nearly $50.0 \%$ of internet's users in the UAE are accessing the web through their cellphones (Ayyad, 2017). The following table show social media traffic across devices among university students in the UAE.

Table 2 shows that nearly $79.0 \%$ of university students are accessing social media across their cellphones. This may be understood in terms of the broadband market in the UAE, as it is one of the most advanced both regionally and globally. As mention above, in 2017, of the 9.58 million people of populations, around 8.81 million (92.0\%) are active internet users. Mobile phone usage in the UAE increased in March 2018 to 228.3 phones per 100 people (BuddeComm Report, 2018), and more than $95.0 \%$ of university students have advanced smartphones: iPhone or Samsung.

Table 2

Social Media Traffic Across Devices ${ }^{*}$ University

\begin{tabular}{llll}
\hline Device of accessing & UoS & ZU & Total \\
\hline Desktop & $16(5.3 \%)$ & $7(5.8 \%)$ & $23(5.5 \%)$ \\
Laptop & $39(13.0 \%)$ & $16(13.3 \%)$ & $55(13.1 \%)$ \\
Cellphone & $237(79.0 \%)$ & $94(78.3 \%)$ & $331(78.8 \%)$ \\
Cyber & $8(2.7 \%)$ & $3(2.5 \%)$ & $11(2.6 \%)$ \\
Total & $300(100.0 \%)$ & $120(100.0 \%)$ & $420(100.0 \%)$ \\
\hline
\end{tabular}

It seems that there are no vital differences in accessing social media across smartphones among students of both surveyed universities. Table 2 shows how students access social media in UoS and ZU. The above table indicates that students in both universities are accessing social media mainly across their cellphones with a percentage of $79.0 \%$. Statistical analysis also shows that there are no significant differences among university students in accessing social media through smartphones.

\section{Research Q2: What Are Main Social Media Accessed by Students Through Their Cell PHONES?}

Main usage of social media. The following table shows the main usage of social media among university's students in the UAE.

Table 3 shows that the most important social medium for the students of universities in the UAE is WhatsApp. This first highly significant preferred website comes with a mean of 4.6 and with a very high statistical significance; this may be understood by recognizing the high capability of WhatsApp to share textual messages related to courses related instructions, which seems to be necessary for the students. 
The second and third social media are Instagram and Facebook, which come with means of 4.24 and 4.2 respectively. The students also access YouTube as a social media with a mean of 3.79 with also a high statistical significance.

Table 3

Preferred Websites (One-Sample T-Test ${ }^{*}$ )

\begin{tabular}{llll}
\hline Social media & Mean $^{* *}$ & Std. Dev. & Sig. $^{* * *}$ \\
\hline WhatsApp & 4.43 & 1.10 & 0.00 \\
Instagram & 4.24 & 1.21 & 0.00 \\
Facebook & 4.20 & 1.32 & 0.00 \\
YouTube & 3.79 & 1.27 & 0.00 \\
Twitter & 2.84 & 1.58 & 0.04 \\
Snapchat & 2.17 & 1.54 & 0.00 \\
Google-plus & 1.97 & 1.42 & 0.00 \\
Flipagram & 1.32 & 0.86 & 0.00 \\
MySpace & 1.30 & 0.83 & 0.00 \\
LinkedIn & 1.23 & 0.73 & 0.00 \\
\hline
\end{tabular}

Notes. ${ }^{*} N($ sample $)=420 ;{ }^{* *}$ Test value $=3 ;{ }^{* * *}$ Confidence interval $=95 \%$, Sig. $=$ Significance, $\mathrm{SD}=$ Standard Definition.

On the other hand, other social media like Snapchat, Google-plus, Myspace, and LinkedIn are rarely preferred by the students. Means of these media are less than 2.83 .

Motivation of using social media. Table 4 shows how social media gratify needs of the students. The most two important reasons for the students to access and use social media are to get information and to communicate with friends and colleagues. The mean of each of the above two reasons exceeds 4.4, with a high statistical significance.

Table 4

Motivations for the Usage of Social Media (One-Sample T-Test ${ }^{*}$ )

\begin{tabular}{llll}
\hline Motivation & Mean $^{* *}$ & SD & Sig. $^{* * *}$ \\
\hline To get information & 4.42 & 0.89 & 0.00 \\
Communicate with friends and colleagues & 4.42 & 0.96 & 0.00 \\
Consuming time & 4.38 & 1.05 & 0.00 \\
To share fun jokes with my friends & 3.95 & 3.63 & 0.00 \\
To follow up public affairs & 3.90 & 1.21 & 0.00 \\
Recording my special moments & 3.89 & 1.30 & 0.00 \\
Recording video clips & 3.82 & 1.30 & 0.00 \\
Feeling lonely without accessing social media & 3.70 & 1.49 & 0.00 \\
Navigation & 3.61 & 1.42 & 0.00 \\
Listening to music and songs & 3.51 & 1.43 & 0.00 \\
Carry out transaction and services & 3.38 & 1.38 & 0.00 \\
Shopping & 3.35 & 1.43 & 0.00 \\
To eliminate the boredom I find in some lectures & 2.76 & 1.41 & 0.00 \\
To get new friends & 2.68 & 1.47 & 0.00 \\
To share funny clips, and jokes with colleagues and friends & 2.67 & 1.58 & 0.00 \\
To avoid feeling ashamed when dealing with others & 2.11 & 1.38 & 0.00 \\
\hline
\end{tabular}

Notes. ${ }^{*} N($ sample $)=420 ;{ }^{* *}$ Test value $=3 ;{ }^{* * *}$ Confidence interval $=95 \%$, Sig. $=$ Significance, $\mathrm{SD}=$ Standard Definition. 
The second most reason for student to access and use social media is to consume time, which comes with a mean of 4.38 , with a high statistical significance.

The students also access the social media for many other important reasons. Means of these reasons exceed 3.5 with a statistical significance. They use the social media to share fun jokes with my friends; to follow up public affairs; to record special moments and video clips; to complete assignments and study duties; to follow up academic status; to navigate the internet; to listen to music and songs because they feel lonely without their cellphones. They also use social media to carry out transaction and services and for shopping.

It seems that the students are active and goal-oriented in using social media to satisfy their individual, social, psychological, and cultural needs.

\section{Research Q3: To What Extent Students Use Social Media for Academic Purposes?}

Using social media for academic purposes. Concerning students' use of social media for academic purposes, Table 5 shows that the students are active in utilizing social media to achieve their academic performance.

Table 5

Motivations for the Usage of Social Media for Academic Purposes (One-Sample Statistics T-Test ${ }^{*}$ )

\begin{tabular}{llll}
\hline Academic purposes & Mean & Std. D. & Sig. \\
\hline Accessing academic and teaching materials & 4.4 & 1.0 & 0.00 \\
Connection with instructors & 4.3 & 1.1 & 0.00 \\
Sharing academic materials & 4.3 & 1.1 & 0.00 \\
Getting new duties & 4.3 & 1.1 & 0.00 \\
Following study instructions & 4.3 & 1.0 & 0.00 \\
Completing assignments and study duties & 3.8 & 1.2 & 0.00 \\
Following up academic status & 3.7 & 1.3 & 0.00 \\
Drop and add courses & 3.6 & 1.4 & 0.00 \\
\hline
\end{tabular}

Notes. ${ }^{*} N($ sample $)=420 ;{ }^{* *}$ Test value $=3 ;{ }^{* * *}$ Confidence interval $=95 \%$, Sig. $=$ Significance, $\mathrm{SD}=$ Standard Definition.

They are using social media for five main purposes: to access teaching materials, to contact instructors, to share educational materials, to get new duties; and to follow up study instructions. Means of these five purposes exceed 4.3 with a high statistical significance.

Students also utilize social media to complete their assignments and duties and follow up their academic status. These findings may be understood in terms of technical facilities produced by universities in the UAE.

Using social media for academic purposes by university. Table 6 shows that there are no significant differences between the students in UoS and ZU universities in utilizing social media for academic purposes. This may be explained in terms of the availability of wireless access to the internet across all campuses of both universities, indoors, and outdoors. Each university has its educational application. Websites of both universities are incorporated with their social media accounts such as WhatsApp, Facebook, and Instagram.

Table 6

Accessing Social Media in Both Universities (Independent Sample T-Test)

\begin{tabular}{lllllll}
\hline University & & $\mathrm{N}$ & Mean & Std. D. & Sig. & F \\
\hline \multirow{2}{*}{ Sum of academic } & UoS & 300 & 18.7 & 3.7 & \multirow{2}{*}{0.47} & 0.51 \\
\hline
\end{tabular}




\section{Research Q4: Are Gender and College of Students Affecting Their Motivations to Use Social Media?}

Gender of students and social media usage and motivations. The following table indicates that gender of students has no significant effect on rate of accessing social media. Sum of means for male students is 28.7 and for female students 29.4. On the other hand, gender of the students has a significant effect on motivations of using social media. It seems that the female students have more motivations (Mean $=70.3$ ) than male students $($ Mean $=66.4)$ to use social media, and with a statistical significant $(\mathrm{Sig} .=0.001)$.

Table 7

Social Media Usage and Motivations ${ }^{*}$ Gender (Independent Sample T-Test)

\begin{tabular}{lllllll}
\hline Sex & & N & Mean & Std. D. & Sig. & F \\
\hline \multirow{2}{*}{ Sum of cellphone use } & Male & 124 & 28.7 & 7.1 & \multirow{2}{*}{0.096} & 2.78 \\
& Female & 296 & 29.4 & 5.8 & & \multirow{2}{*}{11.96} \\
\multirow{2}{*}{ Sum of motivations } & Male & 124 & 66.4 & 16.2 & 0.001 & 12.2 \\
& Female & 296 & 70.3 & & \\
\hline
\end{tabular}

College of students and social media usage and motivations. As for the relationship between college of students and social media' usage and motivations, Table 8 shows that students of both art colleges and sciences colleges have nearly the same mean (69.0) of motivations to use social media.

On the other hand, there some differences of rate of using social media between students of art colleges and sciences colleges. It seems that student of sciences colleges are using social media $(\mathrm{M}=30.6)$ more than students of art colleges $(M=28.2)$, but without statistical significant.

Table 8

Social Media Usage and Motivations ${ }^{*}$ College (Independent Sample T-Test)

\begin{tabular}{lllllll}
\hline College & & $\mathrm{N}$ & Mean & Std. D. & Sig. & F \\
\hline \multirow{2}{*}{ Sum of cellphone use } & Art Colleges & 251 & 28.2 & 6.3 & \multirow{2}{*}{0.06} & 3.67 \\
& Sciences Colleges & 169 & 30.6 & 5.7 & & \\
\multirow{2}{*}{ Sum of motivations } & Art Colleges & 251 & 69.2 & 13.8 & \multirow{2}{*}{0.83} & 0.04 \\
& Sciences Colleges & 169 & 69.0 & 13.3 & & \\
\hline
\end{tabular}

\section{Discussion and Conclusion}

Discussion is dealt with in terms of answering the study's questions and interpreting the theoretical framework. The aim of the study was to investigate gratifications of using social media among university students in the United Arab Emirates. The results of the study show that more than $68.0 \%$ of the university student access social media at least five hours daily and more than $78.0 \%$ of the students are accessing social media through their smartphones. The most frequent social media accessed are WhatsApp, Instagram, Facebook, and YouTube. The students access the social media extensively and use it to gratify their personal, social, psychological, and educational needs. The basic motivations to access social media are to get information and to communicate with friends and colleagues, to consume time, to share fun jokes with friends, to follow up public affairs, and to follow up academic status.

Academic purposes are among the important motivations of accessing social media. The student use social media to access teaching materials, to contact instructors, to share educational materials. The students also utilize social media to complete their assignments and duties and follow up their academic status. The findings 
also indicate that there are some differences in patterns of using social media and motivations obtained refer to gender and academic program of students.

From the above, it is clear that the university students are indeed goal-oriented in their use of social media, using them to gratify their various needs. They use social media to gratify social needs such as communicating with friends and sharing fun jokes with them and knowledge needs such as seeking information and following up public affairs. They also use social media to gratify psychological needs such as consuming time and not to feel lonely; personal needs such as recording special moments and listening to music; and educational needs such as accessing and sharing educational materials, getting new duties, and following up academic status.

Finally, it is important to mention that the limitation of this study is related to its sample. The sample covers only undergraduate students of two universities in the UAE who have similar education levels but belong to slightly different age groups. It is, then, difficult to generalize findings of the study to the regional or the international level. More field studies are needed to examine reasons for the use of social media and gratifications obtained in the Arab countries in relation to personal traits, and social and cultural context.

\section{References}

Alonzo, M., \& Aiken, M. (2004). Flaming in electronic communication. Decision Support Systems, 36(3), 205-213.

Arabian Gazette. (2018). UAE smartphone usage trends. Retrieved 3rd Feb., 2019, from https://arabiangazette.com/uae-smartphone-usage-trends-revealed-2019/

Ayyad, K. (2017). The relationship between sell phone's usage as a communication medium \& academic performance among university students. Arab Journal of Media and Communication, 18, 11-38.

BuddeComm Report. (2017). United Arab Emirates, telecoms, mobile and broadband. Retrieved 2nd Oct., 2018, from https://www.budde.com.au/Research/United-Arab-Emirates-Fixed-Broadband-Market-Statistics-and-Analyses

BuddeComm Report. (2018). United Arab Emirates—fixed broadband market-statistics and analyses. Retrieved 2nd Feb., 2019, from https://www.budde.com.au/Research/2015-United-Arab-Emirates-Telecoms-Mobile-and-Broadband

Chan, K., \& Fang, W. (2007). Use of the Internet and traditional media among young people. Young Consumers, 8(4), $244-256$.

Gan, C., Lee, F., \& Li, Y. (2017). Social media use, political affect, and participation among university students in urban China. Telematics and Informatics, 34, 936-947.

Global Information Technology Report. (2016). World Economic Forum. Retrieved 2nd Oct., 2018, from http://reports.weforum.org/global-information-technology-report2016/economies/\#indexId=NRI\&economy=ARE

Goldfarb, A. (2006). The teaching role of universities in the diffusion of the Internet. International Journal of Industrial Organization, 24(2), 203-225.

Griffiths, M., Kuss, D. J., \& Demetrovics, Z. (2014). Social networking addiction: An overview of preliminary findings. Retrieved from https://www.sciencedirect.com/science/article/pii/B9780124077249000069?via\%3Dihub

International Telecommunication Union Report. (2018). Mobile-broadband statistics, ITU publications: Development (ITU-D). Retrieved 10th Sept., 2018, from http://www.itu.int/en/publications/ITU-D/Pages/default.aspx

Junco, R., Heibergert, G., \& Loken, E. (2010). The effect of Twitter college student engagement and grades. Journal of Computer Assisted Learning, 27(2), 119-132.

Kaye, T., \& Johnson, J. (2004). A web for all reasons: Uses and gratifications of Internet components for political information. Telematics and Informatics, 21(3), 197-223.

Khan, M. (2017). Social media engagement: What motivates user participation and consumption on YouTube? Computers in Human Behavior, 66, 236-247.

Kuss, D. J., \& Griffiths, M. D. (2017). Social networking sites and addiction: Ten lessons learned. International Journal of Environmental Research and Public Health, 14(3), 311-324.

Leung, L. (2003). Impacts of net-generation attributes, seductive properties of the Internet, and gratifications-obtained on Internet use. Telematics and Informatics, 20(32), 107-129.

Lin, C., \& Jeffries, L. (1998). Predicting adoption of multimedia cable service. Journalism Quarterly, 75(2), 251-275.

McQuail, D. (1997). Audience analysis. Thousand Oaks, CA: Sage Publications. 
McQuail, D. (2010). McQuail's mass communication theory (6th ed.). New Delhi: Sage Publications.

Michael, L., Wotring, C. E., \& Forrest, E. J. (1995). An exploratory study of the perceived benefits of electronic bulletin board use and their impact on other communication activities. Journal of Broadcasting and Electronic Media, 39(1), 39-51.

Sapacz, M., Rockman, G., \& Clark, J. (2016). Are we addicted to our cell phones? Computers in Human Behavior, 57, 153-159.

Stephen, J., \& Owen, D. (2004). Internet use and the 2000 presidential election. Electoral Studies, 23(3), 415-429.

Throuvala, M. (2019). Motivational processes and dysfunctional mechanisms of social media use among adolescents: A qualitative focus group study. Computers in Human Behavior, 93, 164-195. 